\title{
FEDERALISMO FISCAL E POLÍTICAS DE COOPERAÇÃO INTERGOVERNAMENTAL FISCAL FEDERALISM AND INTERGOVERNMENTAL COOPERATION POLICIES
}

\section{Denis Sarak*}

\begin{abstract}
SUMÁRIO: 1. Introdução. 2. Noções sobre federalismo. 2.1. O federalismo fiscal. 3. A evolução do federalismo fiscal no Brasil. 3.1. O sistema federativo após a Constituição Federal de 1988. 4. A política de cooperação intergovernamental. 4.1. O grau de cooperação entre a União e os Estados: principais críticas. 4.2. Formação histórica do sistemafederativono Brasil. 4.3. Conflitosideológicos partidários. 4.4. Institucionalização do poder central. 4.5. Perda da autonomia dos Estados frente à municipalização. 5. Conclusão. 6. Bibliografia.
\end{abstract}

- RESUMO: O presente artigo tem por objetivo explorar o tema da cooperação intergovernamental, em especial a relação de cooperação entre os Estados e a União Federal. A questão torna-se muito atrativa, pois, constitui uma forma eficiente de potencializar a prestação de serviços públicos na consecução dos objetivos sociais estabelecidos pela Constituição Federal de 1988. Por meio da cooperação intergovernamental é possível criar uma vinculação política que se estende além dos limites jurisdicionais de cada ente da federação, fazendo com o que os problemas sociais, que muitas vezes são comuns em determinadas áreas, sejam tratados de maneira uniforme por todos os entes federados. A cooperação entre União, Estados e Municípios é uma característica essencial do pacto federativo brasileiro, porém, pouco utilizada pelos nossos governantes. Dessa forma, serão discutidos alguns fatores que inibem essa prática, tais como: a formação histórica do pacto federativo brasileiro, conflitos ideológicos partidários, institucionalização do poder central e a perda de autonomia dos Estados. Compreender as características do sistema federativo brasileiro e identificar as principais dificuldades que impedem a instituição de políticas de cooperação intergovernamental é o objetivo deste estudo.

- Palavras-chave: Federalismo, Cooperação Intergovernamental e Políticas Públicas.

- ABSTRACT: The present article has the purpose to explore the intergovernmental cooperation theme, in particular the relation between the Federal Union and the State. The subject becomes interesting because it constitutes an effective way to maximize the promotion of public services to realize the social objectives established by the Federal Constitution. By the intergovernmental cooperation it is possible to create a political connection which expands beyond the jurisdictional limits of each federal entity, that the social problems, common on certain areas, will be treated equally by all federal entities. The cooperation between Union, States and municipalities is an essential characteristic of the Brazilian Federal agreement, though, less used by our governors. On this matter, will be discussed some issues that difficult the use of this technique, like: History formation of Brazilian's Federalism Agreement, political parties' contradiction, Institutionalize of governmental power and the loss of self-government of the States. The objective of this article is to analyze the characteristics of the Brazilian Federative System and describe the main problems that difficult the relation of the intergovernamental cooperation.

- Key words: Federalism, Intergovernmental Cooperation and Public Policy.

\section{Introdução}

Logo no artigo $1^{\circ}$ da Constituição Federal de 1988, o sistema federativo, assim compreendido em União, Estados, Municípios e Distrito Federal, foi consagrado

\footnotetext{
* Advogado em São Paulo, especialista em Direito Tributário e mestrando em Direito Político e Econômico pela Universidade Presbiteriana Mackenzie. Email: denissrak@hotmail.com
} 
como forma de organização, administração e governo do Estado Brasileiro.

O sistema federativo distingue-se das outras formas de governo principalmente por conferir aos entes federados maior autonomia e interdependência na participação da administração da "res publica".

Tais características permitem maior eficiência na prestação dos serviços públicos em países de grande dimensão territorial, como é o caso do Brasil.

O maior desafio para o sistema federativo é a equalização dos níveis de desenvolvimento e distribuição de riqueza para toda população em seu território. A harmonia entre distribuição de competências e repartição de recursos financeiros é o ponto central para o sucesso desse sistema.

No Brasil, ainda muito se discute sobre como equalizar a política fiscal dentro do sistema federativo proposto pela Constituição de 1988. A repartição das competências legislativas, a distribuição do produto e das fontes da arrecadação fiscal, a incumbência aos entes federados da prestação dos serviços públicos e a cooperação intergovernamental, estão disciplinados no texto constitucional, mas na prática o que temos é um descontrole fiscal e administrativo que impede maior efetividade da prestação do serviço público.

O presente estudo tem como objetivo explorar uma característica essencial do sistema federativo, a cooperação intergovemamental, mais precisamente, a relação da União com os Estados.

Inicialmente será feita uma abordagem sobre as noções gerais do federalismo, com destaque para o Estado Federal e principais características para o federalismo fiscal. Após o estudo apresentará um panorama sobre a evolução do sistema federativo no Brasil, em especial para as mudanças ocorridas após a constituição de 1988. Por ultimo será discutida a questão da cooperação intergovernamental, com destaque para as principais práticas que inibem a cooperação entre a União e os Estados federados e também, alternativas viáveis para possibilitar maior efetividade na prestação do serviço público.

\section{Noções sobre federalismo}

A palavra federal é um derivativo do latim "foedus", que significa pacto ou aliança. O federalismo como forma de administração de um Estado, pode ser entendido como a união ou aliança de diversos Estados-Membros, que sucumbem parte de sua soberania em detrimento da formação de uma entidade nacional com poderes políticos, estabelecidos em sua Constituição.

Sérgio Prado ${ }^{1}$ comenta que "federações são arranjos político-institucionais que visam conciliar a existência de uma nação com autonomia e individualidade política das diversas regiões que a compõe."

\footnotetext{
${ }^{1}$ Cf. PRADO, S. A questão fiscal na Federação Brasileira; diagnósticos e alternativas. Brasília,DF: CEPAL - Comissão Econômica para a América Latina e o Caribe, Escritório no Brasil, mar. 2007.
} 
Luiz Guilherme de Oliveira ${ }^{2}$ explica que:

[...] o essencial no federalismo sempre foi a preservação política simultânea da unidade de objetivos de um povo e da diversidade espacial de seus interesses, compatibilizados na forma de um pacto constitucional em que são simultaneamente, definidos os espaços e os limites das suas soberanias.

O federalismo não pressupõe a existência de hierarquia entre os entes que o compõe, tão somente, há uma repartição de competências instituída na Constituição que delimita o campo de autonomia funcional e administrativa de cada entidade da Federação. Dessa forma, no caso da federação brasileira, União, Estados, Municípios e o Distrito Federal são entidades autônomas e interdependentes.

Sobre autonomia e interdependência destaca Miguel Delgado Gutierrez:

O Estado Federal é, por característica, um Estado descentralizado, no qual reserva uma esfera de ação autônoma a cada unidade federada. A regra nesse tipo de Estado é a distribuição de competências, sem hierarquia. Cada unidade federada tem competência para tratar de determinados assuntos, sem que a União possa se imiscuir neles, nem vice-versa.

Ainda sobre o tema, ressalta Gutierrez ${ }^{4}$ :

[...] laboram em erro os que vêem uma relação hierárquica entre o governo central e os governos locais. O que há, na verdade, são, para cada uma dessas entidades políticas, campos de atuação autônomos e exclusivos, estritamente traçados na Carta Suprema, que lei alguma pode alterar.

Fazendo uma síntese, o sistema federativo é um pacto constitucionalmente estabelecido entre diversos Estados soberanos para a formação de um Estado Nacional, dotado de um poder central, para repartir entre os entes federados, sem prejuízo de suas autonomias, competências e atribuições administrativas com a finalidade de garantir maior efetividade na prestação dos serviços públicos.

O sistema federativo pode assumir a forma dualista, quando se estrutura a partir de duas esferas de poder independentes e autônomas, dotadas de uma repartição de competências e provisão de tributos próprios, ou a forma cooperativa, quando as esferas de poder obedecem a princípios de harmonia, solidariedade e cooperação, na promoção de políticas públicas voltadas para o desenvolvimento global.

${ }^{2}$ OLIVEIRA, Luiz Guilherme de. Federalismo e guerra fiscal:alguns aspectos, alguns casos. São Paulo: Edições Pulsar, 2000. pág. 27, 28.

${ }^{3}$ GUTIERREZ,MiguelDelgado.ParticipaçãodeReceitas Thibutárias: arepartiçãodasfontesdereceita. Receitasoriginárias e derivadas. A distribuição da competência tributánia. In CONTI, José Maurício(Org.). Federalismofiscal. Banueri, SP: Manole, 2004. pág. 37,38.

${ }^{4}$ GUTIERREZ,MiguelDelgado.Participaçãode Receitas Thibutárias: arepartiçãodasfontes dereceita. Receitasoriginárias e derivadas. A distribuição da competência tributária. In CONTI, José Mauńcio(Org.). Federalismo fiscal. Barueri, SP: Manole, 2004. Pág. 38. 


\title{
2.10 federalismo fiscal
}

O federalismo fiscal, em particular, é o modo pelo qual são distribuídos os encargos e as receitas entre os entes federados, com a finalidade de cumprir as incumbências previamente designadas na Constituição. É um sistema de equalização entre competências exclusivas, atribuições funcionais e distribuição de recursos financeiros para a realização de serviços públicos e de toda atividade estatal no território da federação.

Com melhores palavras, Luiz Guilherme de Oliveira ${ }^{5}$ nos ensina:

\begin{abstract}
No federalismo fiscal, como são chamadas as relações de distribuição de receitas e atribuições no regime federativo, o sistema tributário deve ser estruturado de forma a distribuir as receitas públicas entre várias unidades e esferas administrativas, visando proporcionar condições para atender às demandas que lhes são exigidas. Desta maneira se caracteriza a necessidade da existência de uma estrutura capaz de gerar um efeito distributivo entre os grupos que fazem parte da federação, além de um agente intermediador capaz de evitar possíveis atritos entre os membros federados.
\end{abstract}

É por meio da repartição de receitas, que os Estados-membros exercem sua autonomia política na execução dos encargos públicos. A repartição de receitas é determinada pela política fiscal do sistema federativo.

No caso brasileiro, o sistema fiscal é considerado rígido, pois, suas diretrizes normativas estão previstas no texto constitucional e só podem ser alteradas por meio de emenda à Constituição.

A repartição de receitas pode ser efetuada de duas formas, através da repartição das fontes de arrecadação e da repartição do produto de arrecadação.

Sobre este tema, com toda propriedade escreve José Maurício Conti6:

A repartição das fontes de receita é o mecanismo por meio do qual estabelecem-se previamente regras que distribuem as diversas fontes de receita entre o poder central e as unidades subnacionais. Estas regras podem ser fixadas na própria Constituição, como ocorre no caso do Brasil, dando origem ao que se pode denominar de discriminação rígida de rendas. A outra técnica de repartição de receitas é a repartição do produto da arrecadação. Neste caso, a autonomia financeira de uma unidade da federação é assegurada não pela atribuição de fontes próprias de arrecadação, como no sistema anteriormente mencionado, mas sim pela garantia de distribuição de parte do produto arrecadado por uma determinada unidade para outra unidade.

Assim, que é por meio da repartição das receitas que é atribuído grau de maior ou menor autonomia aos entes federados.

${ }^{5}$ OLIVEIRA, Luiz Guilherme de. Federalismo e guerra fiscal:alguns aspectos, alguns casos. São Paulo: Edições Pulsar, 2000. pág. 28.

${ }^{6}$ CONTI, José Maurício. Federalismo Fiscal e fundos de participação. São Paulo: Juarez de Oliveira, 2001. pág.36,37. 
Analisar o sistema fiscal brasileiro, sob a ótica da distribuição de competências e repartição das receitas é o ponto central para começar a refletir as questões do federalismo fiscal.

\section{A evolução do federalismo fiscal no Brasil}

Para chegarmos à temática proposta, será necessária uma breve exposição sobre a evolução do pacto federativo no Brasil, com atenção para as políticas tributárias adotadas nas ultimas Constituições, a fim de contextualizar o sistema atual com as diretrizes traçadas pela norma constitucional.

É certo que o sistema federativo possui raízes desde a Constituição de 1891, que logo em seu artigo $1^{\circ}$ estabeleceu que: "A Nação brasileira adota como forma de Governo, sob o regime representativo, a República Federativa, proclamada a 15 de novembro de 1889, e constitui-se, por união perpétua e indissolúvel das suas antigas Províncias, em Estados Unidos do Brasil."

Desde então o Estado Brasileiro passou por diversos períodos de centralização e descentralização do poder federal, a Constituição de 1934, por exemplo, adotou um sistema federativo mais centralizado, pois, a maior parte das competências era de exercício privativo da União. Esse caráter mais centralizado conferia maior autonomia a União e conseqüentemente reduzia poder dos Estados-membros.

Já na Constituição de 1946, foi elevado o grau de autonomia dos Estados com a concessão de competência privativa para a instituição de alguns impostos como transmissão da propriedade causa mortis, transmissão da propriedade inter vivos, vendas e consignações e outros elencados no artigo 19, além de possuir participação na arrecadação de impostos federais, como o imposto sobre a renda.

A Emenda Constitucional de 1965 também deve ser destacada, pois, criou os Fundos de Participação dos Estados e Municípios, com a destinação de dez por cento do produto de arrecadação do imposto sobre produtos industrializados e imposto sobre a renda, para cada fundo.

De todo caminho percorrido até aqui, pode-se dizer que o sistema federativo no Brasil foi sendo moldado, diante das necessidades históricas vivenciadas em cada período. As Constituições de 1891 e 1934 adotaram uma postura mais centralizada, pois, até aquela época, não havia necessidade de descentralizar grande parte das atribuições e competências para os Estados-membros. O período posterior a Constituição de 1945 passou a ser comandado pelo inicio do processo de industrialização no Brasil e maior era a tendência para descentralização do poder. Com a ditadura militar o poder passou novamente a forma centralizada, e somente com a Constituição de 1988, sob um discurso de redemocratização nacional, foi implementado o sistema federativo atual, novamente descentralizado.

\subsection{O sistema federativo após a Constituição Federal de 1988}

Com a promulgação da Constituição de 1988 o sistema federativo passou a ser revisto. A consolidação da democracia e a retomada do desenvolvimento eram impulsionadas pela descentralização do poder. 
Neste processo de descentralização, a maior novidade foi a elevação dos municípios à condição de ente federado, sendo-lhes conferida maior autonomia e interdependência nas relações políticas do sistema federativo.

Nestes termos, Evandro Costa Gama ${ }^{7}$ explica:

[...] a Magna Carta não só reconheceu a autonomia das entidades subnacionais no art.18, como inovou ao incluir o Município no rol delas. Agora, além da União, dos Estados e do Distrito Federal, os Municípios também integram a organização políticoadministrativa da República Federativa do Brasil.

Luiz Guilherme de Oliveira ${ }^{8}$ complementa dizendo que:

\begin{abstract}
A Constituição de 1988 reduz a participação da União no conjunto tributário nacional, em contrapartida, aumenta as participações tanto de Estados quanto de municípios neste conjunto. Esta descentralização busca aproximar a unidade gestora do gasto e o público-alvo. Porém a estrutura tributária se mantém a mesma, os principais impostos são mantidos semelhantes, modifica-se na verdade, o volume de transferência entre os níveis de administração.
\end{abstract}

Dessa forma, o pacto federativo passou a ter um novo sistema de repartição de competências e gestão dos gastos públicos, além da criação de mecanismos de intervenção federal e o estabelecimento de políticas de cooperação intergovernamental, para a promoção do desenvolvimento regional.

Assim, o sistema federativo da Constituição de 1988 assume um caráter mais voltado para a autonomia e interdependência das entidades federativas, pois, quanto mais descentralizado o poder, maior é a necessidade de equalizar a distribuição dos encargos públicos com a repartição dos recursos financeiros.

Em outras palavras, o equilíbrio político-administrativo em um sistema descentralizado, somente pode ser alcançado através da cooperação e participação de todas unidades da federação no processo de tomada das decisões govemamentais.

É por meio da participação e cooperação intergovernamental, que se pode garantir maior efetividade no estabelecimento e execução de políticas públicas voltadas para o desenvolvimento de todo Estado Federal.

Esse é o espírito do sistema federativo fiscal contido na Constituição de 1988.

\title{
4. A política de cooperação intergovernamental
}

$\mathrm{Na}$ Constituição de 1988 diversos artigos promovem a política de cooperação intergovernamental.

Em seu artigo 23 a Constituição estabelece as competências comuns entre a

${ }^{7}$ GAMA,Evandro Costa. A reforma tributária ea autonomia financeira dasentidadessubnacionais. In CONTI, José Maurício (Org.). Federalismo fiscal. Barueri, SP: Manole, 2004. pág. 141

${ }^{8}$ OLIVEIRA, Luiz Guilherme de. Federalismo e guerra fiscal:alguns aspectos, alguns casos. São Paulo: Edições Pulsar, 2000. pág. 47 
União, Estados, Municípios e Distrito Federal. Essas competências são um importante instrumento de cooperação intergovernamental, pois, confere a todos os entes federados capacidade para elaborar em conjunto políticas públicas de acesso à cultura, educação e ciência, proteção do meio ambiente, promoção de programas habitacionais e combate à marginalização e pobreza.

O artigo 43 da norma constitucional trata da possibilidade da União desenvolver políticas de desenvolvimento e redução das desigualdades regionais em um determinado espaço geoeconômico e social. Esse dispositivo é de grande importância para o incentivo de políticas de cooperação intergovernamental, pois, estimula a criação de planos nacional e regionais para o desenvolvimento sócioeconômico.

O parágrafo terceiro do artigo 25 da Constituição merece destaque, pois, estabelece que: "os Estados poderão, mediante lei complementar, instituir regiões metropolitanas, aglomerações urbanas e microrregiões, constituídas por agrupamentos de municípios limítrofes, para integrar a organização, o planejamento e a execução de funções públicas de interesse comum."

O grande avanço veio com a Lei 11.107 de 2005 que regulamentou a formação dos consórcios públicos e convênios de cooperação entre os entes federados, nos termos do artigo 241 do texto constitucional. Essa lei é um importante exemplo para o federalismo cooperativo, pois, disciplinou a forma de gestão associada de serviços públicos e a transferência de encargos entre as entidades associadas, para o cumprimento das políticas previamente estabelecidas.

O exemplo mais concreto da implementação de políticas públicas por meio de ações intergovemamentais cooperadas é a criação do Sistema Único de Saúde - SUS, nos termos do artigo 198 da Constituição, regulamentado pela Lei 8.080/90, e a criação do Fundo de Manutenção e Desenvolvimento do Ensino Fundamental de Valorização do Magistério - FUNDEF, por meio da Emenda Constitucional 14 de 1996.

Os pontos explorados acima revelam a intenção do legislador constitucional de instituir um sistema federativo sobre bases cooperativas.

Cabe destacar, que muito embora haja vasta previsão constitucional para adoção de políticas de cooperação intergovernamental, poucos são os exemplos bem sucedidos.

O Estado Brasileiro ainda não desenvolveu o espírito de cooperação, seja por razões históricas ou pela existência de diversos fatores que desestruturam o sistema federativo.

Nesse sentido, é comum haver conflitos internos relacionados à distribuição e compartilhamento da receita disponível, disputa pelo controle de gastos e políticas de desenvolvimento regional, além do constante choque de ideologias partidárias.

Esses são alguns obstáculos a serem vencidos para a efetivação de políticas públicas de cooperação intergovernamental, estabelecidas na Constituição de 1988. 


\title{
4.1 O grau de cooperação entre a União e os Estados: principais críticas
}

Em termos de ações conjuntas da União e dos Estados, ainda há muito que se avançar.

A União tentou desenvolver uma política de ação conjunta com os Estados e Distrito Federal, por meio da criação do Conselho Nacional de Política Fazendária CONFAZ, contudo, por nítidas aparências, a experiência não foi bem sucedida.

O CONFAZ é composto por um representante de cada Estado, do Distrito Federal e pelo Ministro de Estado da Fazenda, seu objetivo é desenvolver políticas e normas inerentes ao exercício da competência tributária dos Estados e Distrito Federal.

Ocorre que na prática, ao invés de se estabelecerem políticas conjuntas para o desenvolvimento econômico regional, há um nítido conflito de interesses sobre o favorecimento fiscal de cada região, uma verdadeira guerra fiscal entre os Estados para beneficiar suas próprias regiões. Não há um espírito de desenvolvimento global que possa contemplar a todos.

Essa talvez seja uma das poucas experiências, de cooperação política entre a União, os Estados e o Distrito Federal.

Contudo se analisarmos o conceito de sistema federativo, sua evolução no Estado Brasileiro, as bases constitucionais da Carta de 1988 e ainda o desastre do CONFAZ, podemos enumerar ao menos quatro pontos que obstam a formação de políticas cooperativas entre e União e os Estados.

\subsection{Formação histórica do sistema federativo no Brasil}

Em bases históricas a constituição do sistema federativo no Brasil se deu por meio de segregação, ou seja, não houve a união dos estados-membros na constituição de um Estado Nacional sob uma vontade cooperativa e solidária para promoção do desenvolvimento em conjunto de todos os Estados.

Muito pelo contrário foi o Estado Brasileiro que se dividiu em Estados para melhor administração do território nacional. No decorrer dos anos as políticas públicas privilegiavam setores estratégicos da economia da época, o que aumentava as diferenças regionais e a competição entre os Estados.

Nesse sentido, destaca José Serra?:

\begin{abstract}
Num país sem grandes embates culturais provenientes de diferenças de idiomas, religião ou mesmo étnicas, a federação brasileira foi criada em 1891, após a proclamação da República, como resposta a diferenças regionais e a necessidades administrativas, face à dimensão continental do território. Tal federação não nasceu de alguma coalizão de baixo para cima, mas por decisão de cima, mediante o desdobramento de um Estado unitário. Quanto ao sistema tributário, a federação interessava,
\end{abstract}

${ }^{9}$ SERRA, José; AFONSO, JoséRoberto Rodrigues. Ofederalismo fiscal à brasileira: algumas reflexões. Disponível em: < http://www.bndes.gov.br/> Acesso em 01 out. 2009. fls. 3,4. 
sobretudo, às províncias mais desenvolvidas do Sul e do Sudeste, especialmente São Paulo, onde se concentrava o novo setor exportador. O principal objetivo, entre outros, era a obtenção de maior liberdade de movimentos para impor impostos locais sobre suas exportações. Em troca, às regiões menos desenvolvidas foi oferecida representação mais do que proporcional no Poder Legislativo.

Diante dessa situação, nítida são as diferenças regionais e os interesses particulares dos Estados em promover seu próprio desenvolvimento sem qualquer espírito de solidariedade ou cooperação.

Este aspecto em particular é explorado com mais propriedade por Sergio Prado ${ }^{10}$ :

O baixo grau de cooperação em todas as suas formas é um traço constitutivo nosso federalismo. É possível que este caráter tenha suas origens remotamente localizadas na diferenciação econômica e social das macro-regiões de país continental, que se organizaram política e socialmente em bases locais muito antes que o mercado nacional fosse unificado no período da industrialização; com toda certeza, a concentração da riqueza numa parte da região sudeste foi também determinante para estabelecer clivagens e conflitos horizontais que restringiram sempre a possibilidade de cooperação política e econômica.

\subsection{Conflitos ideológicos partidários}

Outra questão importante a ser destacada é a sobreposição dos interesses Estaduais frente às ideologias partidárias no Senado Federal.

Há pouco compromisso dos senadores com o diálogo dos interesses comuns dos Estados por eles representados, não há o desenvolvimento de um instrumento interlocutório que leve ao governo central a necessidade do estabelecimento de políticas conjuntas entre os Estados e a União, o que há na prática é uma forte concorrência dos interesses partidários.

Sobre este ponto destaca Sérgio Prado ${ }^{11}$ :

Parece pouco questionável a proposição de que o Brasil não apresenta quaisquer traços que lembrem o federalismo cooperativo. Antes de tudo, a participação dos interesses estaduais na legislação federal não é técnico-executiva, como no Bundesrat alemão, mas é intermediada pela estrutura política fragmentária do Congresso nacional e por um Senado tradicional, com representantes eleitos, onde os interesses partidários tendem a filtrar e borrar a representação dos interesses estaduais. Ao

\footnotetext{
${ }^{10}$ PRADO, S. A questão fiscal na Federação Brasileira; diagnósticos e alternativas. Brasília,DF: CEPAL - Comissão Econômica para a América Latina e o Caribe, Escritório no Brasil, mar. 2007. pág. 77

${ }^{11}$ PRADO, S. A questão fiscal na Federação Brasileira; diagnósticos e alternativas. Brasília,DF: CEPAL - Comissão Econômica para a América Latina e o Caribe, Escritório no Brasil, mar. 2007. pág. 76
} 
mesmo tempo, os governos estaduais nunca foram capazes (ou tiveram o interesse) em desenvolver formas voluntárias de organização horizontal, que permitissem articular os seus interesses executivos e encaminhá-los junto ao governo federal.

A ausência de relações horizontais entre os Estado, no sentido da elaboração de diretrizes básicas para a promoção de políticas comuns de desenvolvimento também é fator constituinte do desajuste federativo.

Em melhores termos explica Prado ${ }^{12}$ :

Os governos estaduais brasileiros necessitam evoluir para um padrão de relações horizontais cooperativas, que os constitua como corpo político unificado pelo menos em torno a uma agenda mínima, e dê origem a propostas de reforma que reflitam os interesses do conjunto dos estados. A forma mais indicada para isto é a criação de algo como um Conselho de Estados, permanente e dotado de um secretariado técnico suficiente.

Do mesmo modo, conclui o autor ${ }^{13}$ :

A falta de coesão horizontal dos governos intermediários, em todas as federações, tende a resultar em fragilização da própria estrutura federativa, pois leva ao fortalecimento do governo central. No caso brasileiro, isto tende a se agravar dada a existência de um terceiro nível de governo autônomo, o que permite ao governo central desenvolver formas novas de controle que prescindem da participação estadual.

Dessa forma, tanto a falta de articulação dos interesses comuns dos Estados com o Governo Central, quanto, a prevalência dos interesses partidários no sistema representativo nacional, podem ser consideradas como fatores de influência negativa à promoção de políticas intergovernamentais.

\section{4 Institucionalização do poder central}

Esse fator pode ser associado tanto às mudanças institucionalizadas do sistema federativo no decorrer da história quanto à rigidez constitucional do próprio sistema.

Neste aspecto, as decorrentes mudanças do regime de centralização e descentralização de poder, colocaram o Governo Federal na posição de interlocutor central sobre todas as questões federativas, inibindo a propagação de qualquer cultura de cooperativismo intergovernamental.

Em continuidade, a rigidez do sistema constitucional da mesma forma que impõe o cumprimento de determinadas políticas cooperativas como no caso da saúde e educação, parece não incentivar, ou confortar, o desenvolvimento subjacente de outras formas de cooperação

${ }^{12}$ PRADO, S. A questão fiscal na Federação Brasileira; diagnósticos e alternativas. Brasília,DF: CEPAL - Comissão Econômica para a América Latina e o Caribe, Escritório no Brasil, mar. 2007. pág. 131

${ }^{13}$ PRADO, S. A questão fiscal na Federação Brasileira; diagnósticos e altemativas. Brasília,DF: CEPAL - Comissão Econômica para a América Latina e o Caribe, Escritório no Brasil, mar. 2007. pág. 131 
Sobre o tema, destaca Alessandra Aparecida Souza da Silveira ${ }^{14}$ :

A cooperação intergovernamental tem avançado nos termos da Constituição-regra, do determinismo e da tecnicidade constitucional; não avançou nos termos da Constituição-princípio e do reenvio para densificação legal. Ou seja: a cooperação progrediu naquelas esferas em que o constituinte optou por rigidificar soluções, onde recorreu a uma instrumentalidade normativa marcada pelo perfeccionismo e pelo pormenor.

\subsection{Perda da autonomia dos Estados frente à municipalização}

Outra importante crítica é a elevação dos Municípios à condição de ente federado.

Como já dito, essa mudança foi introduzida pela Constituição Federal de 1988 e provocou uma verdadeira reforma no conceito de governança federativa. A idéia inicial era desencadear um novo processo de descentralização do poder, conferindo maior autonomia aos Estados e Municípios, de modo a atingir maior efetividade na prestação dos serviços públicos.

Ocorre que, houve um intenso processo de criação de municípios que passaram a concorrer diretamente com os Estados na articulação do desenvolvimento de políticas públicas junto a União.

A grande discussão desse tema se volta para a desestruturação de todo sistema federativo, pois, além de contribuir diretamente com a perda de autonomia dos Estados na participação efetiva de programas de desenvolvimento regional, muitos Municípios não possuem sequer estrutura técnica e administrativa para a realização de tais políticas em conjunto com a União.

Nestes termos, merece destaque as palavras de Alessandra A. Souza da Silva ${ }^{15}$ :

Em doze anos (1988-2000) foram criados 1200 Municípios entre os 5507 existentes. Um expressivo número de Municípios brasileiros (84,2\%) têm até 30.000 habitantes (correspondentes a 29\% da população) e a maioria deles não é auto-sustentável: alguns dependem quase que exclusivamente das transferências centrais. Em conseqüência disto, os Municípios procuram estreitar laços com o governo federal e priorizam as relações diretas/ bilaterais que facultem apoio financeiro via transferências específicas. A tendência também aproveita ao Estado central, que prefere interlocutores desarticulados e financeiramente mais débeis que os Estados federados. Conclusão: sem mecanismos cooperativos e alguma interdependência decisória, o autogoverno municipal resulta falacioso.

\footnotetext{
${ }^{14}$ SILVEIRA, Alessandra Aparecida de Souza, "A cooperação intergovernamental no Estado composto brasileiro: analise jurídico- constitucional", VII Congresso da CLAD, Portugal, outubro 2002. Pág.10. ${ }^{15}$ SILVEIRA, Alessandra Aparecida de Souza, "A cooperação intergovernamental no Estado composto brasileiro: analise jurídico- constitucional", VII Congresso da CLAD, Portugal, outubro 2002. Pág.10.
} 
Sobre a concorrência direta com os Estados, Sérgio Prado ${ }^{16}$ comenta:

\begin{abstract}
O significado maior da reforma de 1988 reside, com certeza, na forte ampliação do poder político municipal na federação brasileira. O que ocorreu a partir dali foi o aprofundamento da articulação direta entre governo federal e municípios, que tinha já antecedentes remotos na dualidade dos fundos de participação, criada em 1967. A partir das disposições constitucionais de 1988 deslancha-se o processo de descentralização/ municipalização, que ampliou os laços financeiros entre a União e os municípios, aprofundamento a marginalização dos estados no que concerne aos negócios municipais.
\end{abstract}

De fato, a questão da municipalização veio a interferir diretamente na relação de cooperação entre os Estados e a União, porém, não pode ser julgada como fator isolado, pois, como já analisado, o problema da cooperação intergovemamental possui traços estruturais originários desde a criação do sistema federativo pela Constituição de 1891.

Entender e interpretar as críticas aqui expostas, sobre um contexto sócio, econômico, histórico e cultural é o primeiro passo a ser dado a caminho de propostas sólidas para a reforma federativa fiscal no Brasil.

\title{
5. Conclusão
}

Uma das deficiências do novo pacto federativo criado pela Constituição de 1988 é a integração de políticas governamentais entre os Estados-membros da federação.

Não há como contestar que o sistema federativo, tal como proposto, é o modelo que melhor se adapta as regras constitucionais vigentes. Ele é capaz de viabilizar e possibilitar maior efetividade na prestação dos serviços públicos diante das constantes mudanças de uma sociedade globalizada e da própria rigidez do sistema imposto.

No entanto, o espírito de cooperação e solidariedade, tal como pressupostos do novo sistema, ainda não foi bastante difundido nas relações intergovernamentais, o que acaba por comprometer toda efetividade perseguida pelo texto Constitucional.

Questões históricas, culturais, ideologias partidárias distintas e concorrência direta entre os entes federativos, parecem ser os principais problemas a serem enfrentados.

A relação direta dos Estados com a União, quando o assunto é cooperação intergovernamental é praticamente nula ou insignificante.

Entre os próprios Estados, parece não haver consenso ou previsão de união, para ao menos sequer, apresentarem diretrizes conjuntas para o incentivo do desenvolvimento de políticas públicas voltadas a assuntos de interesse comum. A falta de cooperação e o ambiente hostil de competição entre os Estados agravam ainda mais o problema.

${ }^{16}$ PRADO, S. A questão fiscal na Federação Brasileira; diagnósticos e altemativas. Brasília,DF: CEPAL - Comissão Econômica para a América Latina e o Caribe, Escritório no Brasil, mar. 2007. Pág. 123. 
A questão da cooperação intergovernamental entre os Estados e a União Federal, é apenas um dos diversos pontos a serem explorados para uma proposta de reforma fiscal condizente com as necessidades da República Federativa do Brasil.

\section{Bibliografia}

CONTI, José Maurício (Org.). Federalismo fiscal. Barueri, SP: Manole, 2004.

CONTI, José Maurício. Federalismo Fiscal e fundos de participação. São Paulo: Juarez de Oliveira, 2001.

CUNHA, R. E. da. Federalismo e relações intergovernamentais: os consórcios públicos como instrumento de cooperação federativa. Revista do Serviço Público, Ano 55, n. 3 , jul-set, 2004.

OLIVEIRA, Luiz Guilherme de. Federalismo e guerra fiscal:alguns aspectos, alguns casos. São Paulo: Edições Pulsar, 2000.

PRADO, Sérgio. Equalização e federalismo fiscal: uma análise comparada. Rio de Janeiro: Konrad-Adenauer-Stiftung, 2006.

PRADO, S. A questão fiscal na Federação Brasileira; diagnósticos e alternativas. Brasília,DF: CEPAL - Comissão Econômica para a América Latina e o Caribe, Escritório no Brasil, mar. 2007.

RESENDE, Fernando (Org.). Desafios do federalismo fiscal. Rio de Janeiro: Editora FGV, 2006.

SERRA, José; AFONSO, José Roberto Rodrigues. O federalismo fiscal à brasileira: algumas reflexões. Disponível em: < http://www.bndes.gov.br/> Acesso em 01 out. 2009.

SILVEIRA, Alessandra Aparecida de Souza, "A cooperação intergovernamental no Estado composto brasileiro: analise jurídico- constitucional", VII Congresso da CLAD, Portugal, outubro 2002. 
